\title{
How much should the public know about climate science?
}

\section{An editorial comment}

\author{
Richard C. J. Somerville
}

Received: 8 June 2010 / Accepted: 8 July 2010 / Published online: 21 October 2010

(C) The Author(s) 2010. This article is published with open access at Springerlink.com

The article in this issue of Climatic Change, by Shepardson et al., "Student Conceptions about the Greenhouse Effect, Global Warming, and Climate Change," is more than a science education assessment study. This article confirms and adds to our understanding of what the broad public does and does not know about the science of climate change, and it raises several important questions. The subset of the public sampled in this research consists of 51 students, 39 in junior high school and 12 in high school, all of whom attend schools in small rural communities in the mid-western United States. We are told only a few other facts about these 51 students, such as that they completed the assessment study, "prior to any classroom instruction on the greenhouse effect, global warming, and climate change."

As the authors state, student responses were not scored as "right" or "wrong." However, almost any climate scientist will surely want to know whether the responses are correct or not. Indeed, they are a fascinating mixture of right and wrong. Some student answers are scientifically accurate and perceptive, while other answers are wildly incorrect and seemingly unrelated to physical reality. In this respect, they are consistent with what many other studies and much polling data have shown, namely that the broad public, in many other countries as well as in the United States, is generally not well informed about the science of climate and climate change. Like the secondary school students assessed by Shepardson et al., many adults worldwide often believe wildly inaccurate ideas about climate change science. Some major misconceptions, such as confusing the greenhouse effect with the ozone hole, occur so often that they no longer surprise climate scientists who frequently give public lectures on climate change.

Seeing the results presented by Shepardson et al. immediately reminded me of two memorable films that have achieved iconic stature in the science education community: A Private Universe and Minds of our Own-Lessons from Thin Air.

R. C. J. Somerville ( $₫)$

Scripps Institution of Oceanography, University of California,

San Diego La Jolla, CA 92093-0224, USA

e-mail: rsomerville@ucsd.edu 
Both of these videos may be purchased as DVDs and are also easy to find online, where they may be viewed at no cost. Both videos include memorable scenes from graduation days at Harvard and MIT. In A Private Universe, which dates from the 1980 s, nearly all the randomly chosen interview subjects (new university graduates, alumni, and faculty) were unable to give a correct explanation of the cause of seasons. The most popular wrong explanation offered was that the Earth was closest to the sun in summer, and farthest away in winter. The well-educated people who gave this answer may have forgotten the correct explanation, that seasons are due to the Earth's axis of rotation being tilted, rather than perpendicular to the plane of the Earth's orbit around the sun. However, they also had clearly not thought through the issue carefully before giving their answer. For example, they did not seem to have considered several obvious difficulties with their "distance-from-Earth-to-sun" theory, such as that the northern and southern hemispheres of our planet have seasons that are six months out of phase with one another.

Minds of our Own-Lessons from Thin Air was made about a decade later than $A$ Private Universe. One unforgettable sequence from this video consists of graduation day interviews, again at renowned universities. This time, each subject was first asked to hold both a tiny seed and a log weighing several kilograms. Then the interviewer's question was where does all the mass in a mature tree comes from, mass that was obviously not present in the tiny seed from which the tree began? As with many of the secondary school students studied by Shepardson et al., these university graduates typically gave wrong answers. Most of them cited water and minerals in the soil being captured by the roots of the tree. Indeed, it is not obvious to an uneducated person how a tiny seed becomes a tree weighing several tons. However, the process responsible for this growth, photosynthesis, is taught in secondary schools everywhere as well as in great universities. Nevertheless, despite their having studied photosynthesis during their educations, these well-educated people forgot about it while being interviewed. These graduates of the most elite American universities clearly did not know that nearly all the mass in a tree comes from the carbon dioxide in the air.

Both the cause of seasons and the role of $\mathrm{CO}_{2}$ in tree growth are relevant to climate change, and I think the widespread public ignorance of these scientific explanations illustrates an important educational failure. I am confident that many of the secondary school students who know very little about climate science today will grow up to be adults, some of them having earned university degrees, who unfortunately will still know very little about climate science. We should ask why, and I would answer that much of the blame lies in how we typically educate students about science. Knowledge, including knowledge about climate science, should never be taught as a catalogue of boring and unrelated facts to be memorized for the purpose of passing tests.

Science is a process, a way of regarding the natural world, and a fascinating human activity. A textbook may state that carbon dioxide makes up about $0.038 \%$ by volume of dry atmospheric air. It is all well and good to learn this, but the number $0.038 \%$ by itself is just an isolated fact, without much significance. It is much better if the student will also learn who was first able to measure atmospheric carbon dioxide concentration accurately, and when, and how the measurement was made, and whether this number has changed over time, and if so, why, and something about the importance of this number to the greenhouse effect and climate change. 
For many students to achieve that level of understanding will require a major change in current educational practices. A great deal is already known about how to do a better job of science education, but implementing such profound change is not easy, and completing the task will take many years at best.

I am confident that any successful resolution of this task will involve constructivist learning theory, which traces its roots to the twentieth-century Swiss epistemologist Jean Piaget, among others. This theory emphasizes the role of the teacher as supportive facilitator rather than didactic lecturer, "a guide on the side, not a sage on the stage." It also stresses the importance of the teacher making a serious effort to understand and appreciate the prior knowledge of the student, recognizing that students' minds are not empty vessels to be filled or blank slates to be written on. Instead, students come to class with a background of life experiences and a body of existing knowledge, of varying degrees of correctness or accuracy, about almost any topic. Constructivist teaching methods also stress making use of the parallels between learning and scientific research, such as the analogies between assessing prior knowledge in the classroom and surveying scientific literature for a research project.

The assessment methodology used by Shepardson et al. is given in Appendix A of their paper and involves several questions and two graphs. Within the climate science community, the two graphs are both very well known. The "assessment instrument" (the set of questions which the 51 students were to answer), states that the first graph depicts "the change of temperature and atmospheric carbon dioxide $\left(\mathrm{CO}_{2}\right)$ over the past centuries." The students were given no other information about this graph.

We climate scientists, however, know that this graph, covering the period of about the last 400,000 years, is derived from the ice core record. In fact, ice cores available now have extended our knowledge of climate back in time for several hundred thousand years beyond the period shown in the graph. In the cores, deuterium variations are a proxy for local temperature, and $\mathrm{CO}_{2}$ can be measured in the tiny quantities of air trapped in the ice. The fortuitous existence of deep ice cores in Greenland and Antarctica preserves this trapped air and allows us to sample and directly measure the chemical composition of the ancient atmosphere.

The dominant feature appearing in the temperature record on this graph is the roughly 100,000 year glacial-interglacial cycle. A relatively small fraction, averaging about $20 \%$, of this cycle is spent in the warm interglacial phase, which typically lasts about 10,000 to 20,000 years. We are living in the most recent of these interglacials, the Holocene. The most recent glacial period began about 116,000 years ago and culminated in the Last Glacial Maximum (LGM) about 21,000 years ago.

To the eye, the co-variation of temperature and $\mathrm{CO}_{2}$ on this graph is obvious, but the full story is complex. In fact, careful research published in the last decade has clearly shown that during the deglaciation transition from full glacial conditions to warm interglacials, the $\mathrm{CO}_{2}$ does not begin to rise synchronously with the rise in Antarctic temperature. Instead, the $\mathrm{CO}_{2}$ lags behind the temperature, typically by several centuries. Thus, $\mathrm{CO}_{2}$ variations do not directly "cause" ice ages and interglacials. There is persuasive scientific evidence that the temperature changes themselves are initiated by periodic changes in the Earth's orbit around the sun, the so-called Milankovitch mechanism. This mechanism alters the distribution of sunlight with season and latitude, without significantly affecting the global annual mean. 
The beginnings and ends of ice ages are thus paced or triggered by predictable orbital variations. Then processes in the climate system cause the $\mathrm{CO}_{2}$ amount to change in the same direction as the temperature changes. $\mathrm{CO}_{2}$ decreases as temperature falls entering a glacial period, and increases as temperature rises entering an interglacial period. These $\mathrm{CO}_{2}$ variations then alter the radiative forcing, or greenhouse effect, and thus feed back on the climate change, amplifying the temperature changes that triggered the $\mathrm{CO}_{2}$ changes. Much remains to be learned. In the words of the 2007 Fourth assessment Report of the IPCC, "The quantitative and mechanistic explanation of these $\mathrm{CO}_{2}$ variations remains one of the major unsolved questions in climate research." Thus, we see that the questions posed by Shepardson et al. concerning this graph (i.e., would climate change if $\mathrm{CO}_{2}$ did not, and why or why not?) are actually quite profound, and simply looking at the graph cannot possibly lead to a full understanding of them.

The other graph used in the assessment instrument of Shepardson et al. is undoubtedly the most famous graph in all Earth science, the Keeling curve. This graph depicts the $\mathrm{CO}_{2}$ concentration measured since 1958 at the Mauna Loa observatory, initially by Charles David Keeling (1928-2005), using an instrument he designed and constructed himself. These data and the analysis of them, which are explicitly or implicitly referred to in every discussion of global warming, are the bedrock evidence that mankind has changed the chemical composition of the atmosphere, in particular by increasing the $\mathrm{CO}_{2}$ concentration, mainly by burning fossil fuels. Much could be and has been said about this graph, but the simplest correct answer to the questions about natural and human processes affecting $\mathrm{CO}_{2}$ amounts, posed by Shepardson et al., is this: The strongly increasing trend of atmospheric $\mathrm{CO}_{2}$ concentration is humancaused, while the annual oscillations in $\mathrm{CO}_{2}$ amounts are due to the global effect of photosynthesis and respiration.

Even these statements are based on some serious research, much of it done by Keeling himself. They cannot be demonstrated simply from the graph. The evidence that the increase in $\mathrm{CO}_{2}$ amounts is man-made involves isotopic analysis of atmospheric $\mathrm{CO}_{2}$ to distinguish between $\mathrm{CO}_{2}$ from fossil fuels and $\mathrm{CO}_{2}$ from other sources. The ratio of the stable isotopes carbon-13 and carbon-12 in atmospheric $\mathrm{CO}_{2}$ changes predictably as fossil fuel $\mathrm{CO}_{2}$ is added to the atmosphere, because fossil fuels are relatively depleted in carbon-13. This ratio is also sensitive to other sources and sinks, but the isotopic fossil fuel signal can be distinguished from other components and measured using modern isotope ratio mass spectrometry.

The $\mathrm{CO}_{2}$ growth rate has increased substantially over the period of record. It was 1.4 ppm per year on average from 1960 to 2005 , but 1.9 ppm per year for the decade from 1995 to 2005, the highest recorded for any decade since measurements began. The annual cycle follows the Northern Hemisphere seasons and is due to seasonal changes in photosynthesis in the terrestrial biosphere, with $\mathrm{CO}_{2}$ decreasing in Northern spring as plants put out leaves and photosynthesize, and increasing in Northern fall when they respire. The Northern Hemisphere dominates, because it contains most of the land, hence most of the plants. The increasing atmospheric $\mathrm{CO}_{2}$ concentration due to human activities is the single most important factor causing global warming, but there are many others. The observed increasing acidification of the world oceans, which may have profound biological implications, is also a serious consequence of adding $\mathrm{CO}_{2}$ to the atmosphere. 
Unfortunately, the world needs to take firm action about the threat of manmade climate change within the next decade. Figure 1 summarizes recent research showing that global emissions of greenhouse gases must peak and decline within the next decade if global warming is to be limited to a level that avoids severe climate disruption. Realistically, there may be no chance to educate the general public in depth about the science so quickly. Meanwhile, a well-funded and effective professional disinformation campaign has been successful in sowing confusion, and many people mistakenly think climate change science is unreliable or is controversial within the expert community. Thus, the more urgent task for us scientists may well be to give the public guidelines for recognizing and rejecting junk science and disinformation. If students today, who will be adults tomorrow, can understand and apply these guidelines, they may not need a detailed knowledge of climate change science. To that end, I offer the following six principles.

1. The essential findings of mainstream climate change science are firm. The world is warming. There are many kinds of evidence: air temperatures, ocean temperatures, melting ice, rising sea levels, and much more. Human activities are the main cause. The warming is not natural. It is not due to the sun, for example. We know this because we can measure the effect of man-made carbon dioxide and it is much stronger than that of changes in the sun, which we also measure.

2. The greenhouse effect is well understood. It is as real as gravity. The foundations of the science are more than 150 years old. Carbon dioxide in the atmosphere traps heat. We know carbon dioxide is increasing because we measure it. We know the increase is due to human activities like burning fossil fuels because we can analyze the chemical evidence for that.

3. Our climate predictions are coming true. Many observed climate changes, like rising sea level, are occurring at the high end of the predicted range. Some observed changes, like melting sea ice, are happening faster than the anticipated

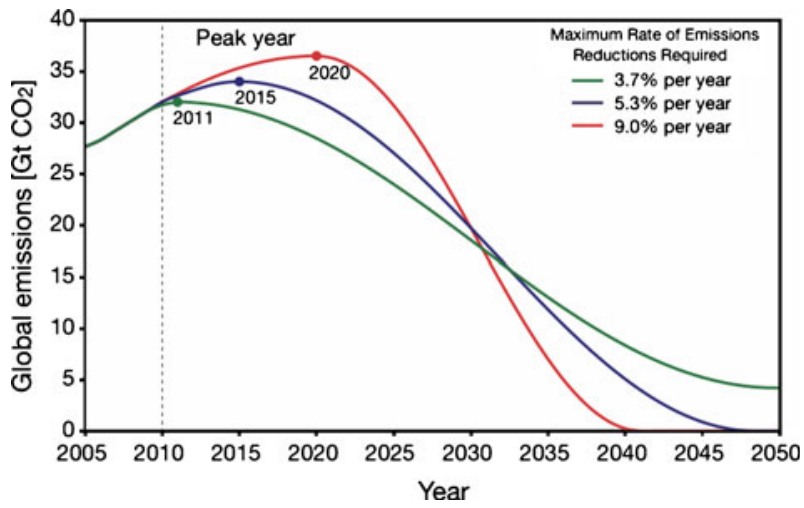

Fig. 1 Emissions pathways to give a $67 \%$ chance of limiting global warming to $2^{\circ} \mathrm{C}$ above preindustrial temperatures. From: The Copenhagen Diagnosis, Updating the World on the Latest Climate Science (www.copenhagendiagnosis.com). Originally from German Advisory Council on Climate Change, Solving the Climate Dilemma: The Budget Approach, WBGU, Berlin, 2009. Creative Commons license: http://creativecommons.org/licenses/by-nc-nd/2.0/de/deed.en 
worst case. Unless mankind takes strong steps to halt and reverse the rapid global increase of fossil fuel use and the other activities that cause climate change, and does so in a very few years, severe climate change is inevitable. Urgent action is needed if global warming is to be limited to moderate levels.

4. The standard skeptical arguments have been refuted many times over. The refutations are on many web sites and in many books. For example, the mechanisms causing natural climate change like ice ages are irrelevant to the current warming. We know why ice ages come and go. That is due to changes in the Earth's orbit around the sun, changes that take thousands of years. The warming that is occurring now, over just a few decades, cannot possibly be caused by such slowacting processes. But it can be caused by man-made changes in the greenhouse effect.

5. Science has its own high standards. It does not work by unqualified people making claims on television or the Internet. It works by expert scientists doing research and publishing it in carefully reviewed research journals. Other scientists examine the research and repeat it and extend it. Valid results are confirmed, and wrong ones are exposed and abandoned. Science is self-correcting. People who are not experts, who are not trained and experienced in this field, who do not do research and publish it following standard scientific practice, are not doing science. When they claim that they are the real experts, they are just plain wrong.

6. The leading scientific organizations of the world, like national academies of science and professional scientific societies, have carefully examined the results of climate science and endorsed these results. It is silly to imagine that thousands of climate scientists worldwide are engaged in a massive conspiracy to fool everybody. It is also silly to think that a few minor errors in the extensive IPCC reports can invalidate the reports. The first thing that the world needs to do to confront the challenge of climate change wisely is to learn about what science has discovered and accept it. The IPCC Fourth Assessment Report at www.ipcc.ch is a good place to start.

Open Access This article is distributed under the terms of the Creative Commons Attribution Noncommercial License which permits any noncommercial use, distribution, and reproduction in any medium, provided the original author(s) and source are credited. 